\title{
MODELING AND ASSESSMENT OF THE IMPACT OF LAND USE IN THE WESTERN RIF REGION, MOROCCO, ON WATER QUALITY
}

\author{
Ghizlane Fattah $^{1^{*}}$, Fouzia Ghrissi ${ }^{1}$, Jamal Mabrouki ${ }^{2}$ and Naif Al-Jadabi ${ }^{2}$ \\ ${ }^{1}$ Civil hydraulic and environmental engineering laboratory, Water treatment and reuse structure, Mohammadia School of Engineers, \\ Mohammed V University in Rabat, Avenue Ibn Sina B.P 765, Agdal Rabat, 10090 Morocco \\ ${ }^{2}$ Laboratory of Spectroscopy, Molecular Modeling, Materials, Nanomaterial, Water and Environment, CERNE2D, Mohammed V \\ University in Rabat, Faculty of Science, Avenue Ibn Battouta, BP1014, Agdal, Rabat, Morocco
}

KEY WORDS: Modeling, impact, water quality, Western Rif, Morocco

\begin{abstract}
:
The Western Rif is a rural area characterized by rock extraction and agriculture. As a result, the surface of the land in the region is exposed to different sources of contamination which alters the quality of the soil. Leaching of the soil and runoff to surface water may impact the quality of surface water used by local people. A mapping of the land use by GIS of an area located at the level of the western Rif was carried out then an analysis of the interactions between the uses of the land; the practices, the quality of the surface layer of the soil and the quality of the water were made. Thanks to the processing of satellite images and to samples on the ground and assays of the physic-chemical parameters of soils and water ( ${ }^{\circ}, \mathrm{pH}, \mathrm{MES}$, turbidity, Nitrate, nitrite, phosphorus, nitrogen, etc.). The results of these analyzes revealed that these activities lead to an alteration in the quality of the surface layer of the soil, its characterization of which changes depending on the land use. Surface water is endowed with the components identified in the soil. This reveals that land use has generally negative physical and chemical impacts on surface waters.
\end{abstract}

\section{INTRODUCTION}

The exploitation of quarries and the production of aggregates constitute a very important sector for the socio-economic development of the country (Al Rawashdeh et al; 2016). Indeed, this sector is located upstream of the activities linked to the realisation of a large number of urban development projects (Ayenagbo et al; 2011). The bodies responsible for carrying out these actions have to extract materials and ores of all kinds to carry out their mission (Garcia-del-Real et al; 2020). Indeed, quarrying is the basis of all infrastructures. We need only recall its geological definition to realise this. It is an artificial excavation, generally open air, used for the extraction of construction materials (limestone, granite, gypsum, sand....) (Habert et al; 2020).

Furthermore, it is obvious that quarrying requires the occupation of space. However, this occupation is temporary, since at the end of the operation, the said space must be restored (Mor et al; 2019). If the exploited sites are not rehabilitated, the quarry holes become groundwater recharge areas due to their shallowness and the permeability of the underlying layers. Abandoned quarries can also become uncontrolled dumps or unhealthy housing sites ( Mabrouki et al; 2020).

It is obvious that quarrying has an impact on water. Whether they are out of water or in water, quarries can directly or indirectly influence the hydrological characteristics of wadis and the hydrogeology of groundwater. By changing the course of surface water, an out-of-water quarry can modify, or even eliminate, part of the groundwater recharge, whereas an inwater quarry can induce, particularly during flood periods, new preferential flows that modify, aggravate or attenuate the effects of the flood locally.

\section{MATERIALS AND METHODS}

\subsection{Study site}

The study area is located in the heart of the Tingitane peninsula, more precisely north of the city of Tetouan on the western Rif which is made up of a mountain range stretching out over the Mediterranean Sea. They are characterized by the presence of rivers constituting small watersheds. Geologically, it is formed as a tectonic unit made up of the fragmented and nested structural units of limestone and dolomite from the Triassic and Early Jurassic. This limestone chain, which is characterized by a humid climate and by an intense karstification system that has generated several karsts ranging from limestone causeways to pits, caves, dry valleys and travertine deposits (, constitutes aquifers which benefit from the infiltration of rainwater (Fattah, et al ; 2021).

\subsection{Sampling}

The purpose of water sampling is to provide qualitative and quantitative information and to specify the hydrodynamic properties of the observed systems. To obtain appropriate information the following conditions must be met: Specific sampling systems are needed to preserve the original information on the qualitative and quantitative properties of the subsurface water (Gong et al; 2021). At the sampling point the water taken must represent groundwater at the same depth in the system and must not be disturbed by the construction of the well. Using your arm below the water surface, uncork and fill the $500 \mathrm{ml}$ bottle, rinse it and then empty it out of the water (Said et al; 2019). Quickly reform the bottle and immerse it in the water to the desired depth. If no precise indication is given, take the sample from $30 \mathrm{~cm}$ below the surface of the water (Pan et al; 2021). 


\subsection{Physicochemical analysis}

The characterisation of surface waters is mainly concerned with the analysis of basic parameters $(\mathrm{pH}$, temperature and conductivity) of major ions and possible trace elements. ... Conductivity, temperature and $\mathrm{pH}$ define the basic characteristics of the water (Suaria et al; 2020). Phosphates, ammonia, nitrates and iron make it possible to assess the impact of polluting discharges. Bacteriological analyses generally confirm the microbial pollution of these surface waters and make it possible to determine its importance. Biological indices are especially interesting for running water. The study periods and stations must be chosen to best define the spatial and temporal variability of the quality of the environment (see paragraph on sampling) (Aboubakar et al; 2021).

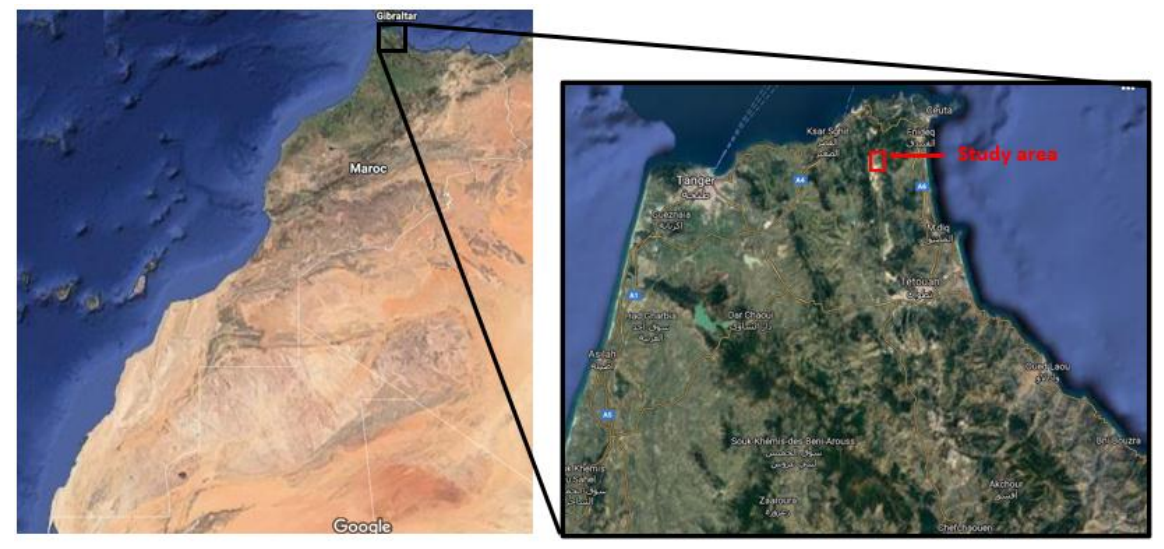

Figure 1 : Study area location

\subsection{Equation and modeling}

In mechanics of fluids, the momentum balance equation is derived from the fundamental principle of dynamics applied to a fluid. Together with the conservation of momentum equation and the heat equation it is part of the Navier-Stokes equations. With this approximation, we sought to simulate the nitrogen, phosphate and oxygen cycles of the process. This approximation transforms a continuous problem governed by the differential equations into a discrete problem, so using an initial concentration of $\mathrm{CO}$ (which must be known), we can derive other concentrations at different times and locations.

$$
\frac{d C}{d t}=D_{x} \frac{d^{2} C}{d_{x}^{2}}-V_{x} \frac{d C}{d x}-K C \pm S_{\text {Interne }}
$$

With :

K est le coefficient de réaction de la vitesse Dx is the longitudinal dispersion Coefficient Sinterne are source terms

$\mathrm{Vx}$ is the flow velocity in the spatial direction $\mathrm{x}$.

The individual response coefficients vary over defined ranges, enabling our model to be tuned to fit the conditions and the characteristics of the study area. The source terms (gain or loss) are associated with phenomenon that influences the concentration of the parameters. These sources are important when liquids loads are dumped into the stream (domestic, agricultural and industrial fluids (Mabrouki et al; 2019). The calibrated model was tested only in the downstream region that has suffered a recent severe degradation. Different solutions were tested, allowing the study of possible enhancements to reduce the water quality degradation. The geometry of the configurations consisted of seven sections (Figure 1), with varying dimensions. Each section was named after the nearest village or locality.

To estimate the overall water quality in the lower portion, the water quality index was derived using simulated data and laboratory readings. This index ranks water quality on a 0-60 scale, where the 20-50 range represents very poor water quality status, while $0-25 \%$ represents excellent water quality. The NSF-WQI was calculated using the arithmetic index method (Zotou et al; 2020) using the equation:

$$
N S F-W Q I=\sum_{n=1}^{n} q_{n} W_{n} / \sum_{n=1}^{n} W_{n}
$$

Where, qn (Eq.2) is the grade that mirrors the relative value of the variables with the permitted standard value (Chowdhury et $\mathrm{al} ; 2020)$. The qn is derived from the ideal value (Vi) which is equal to zero $\mathrm{Vi}=0$, except for $\mathrm{pH}(\mathrm{Vi}=7)$, temperature (T) $(\mathrm{Vi}=25)$ and $\mathrm{DO}(\mathrm{Vi}=14.6 \mathrm{mg} / \mathrm{L})$, the observed value $(\mathrm{Vn})$, the standard of the measured parameters allowed value $(\mathrm{Sn})$.

$$
q_{n}=100\left[V_{n}-V_{i}\right] /\left[S_{n}-V_{i}\right]
$$

Wn is the unit burden of the nth water quality characteristic (Prasad et al; 2021), it is calculated using equation 4 :

$$
\mathbf{w}_{\mathbf{n}}=\mathbf{k} / \mathbf{s}_{\mathbf{n}}
$$

Where $\mathrm{K}$ is the proportionality constant and is determined by the formula 5 :

$$
\mathbf{K}=\mathbf{1} /\left(\sum \mathbf{1}\left(\mathbf{S}_{\mathbf{n}}=1,2, \ldots, \mathbf{n}\right)\right)
$$


Since the temperature (T), $\mathrm{pH}$, electrical conductivity (EC), and water hardness (hydrotimetric titer $\mathrm{TH}$ ) are not governed by the mass balance equation, we used stepwise regression methodology to reveal the existing simulated parameter correlation. This Regression method estimates the necessary parameters for the WQI-FNS using a combination of a simulator.

\section{RESULTS AND DISCUSSION}

\subsection{Water characterisation}

The $\mathrm{pH}$ value determines the acidity, alkalinity and neutrality of solutions. It is related to the nature of the soil. Figure 2 shows the results of $\mathrm{pH}$ measurements at the various sites. This parameter characterises a large number of physico-chemical equilibria and depends on multiple factors including the origin of the water. The $\mathrm{pH}$ values in general are basic in all points with a minimum of 7.5 in site $\mathrm{S} 1$.

Electrical conductivity measures the ability of water to conduct electrical current, as most of the dissolved material in water is in the form of electrically charged ions and varies proportionally with temperature fluctuations. Its variation, which provides information on mixing or infiltration zones, makes it possible to monitor the evolution of chemical pollution (Paule-Mercado et al; 2018). Figure 2 shows the results of water conductivity measurements in the different wetlands visited during different periods. This high relative conductivity, reflecting a high mineralization, could be attributed to the decrease in the quantity of water.

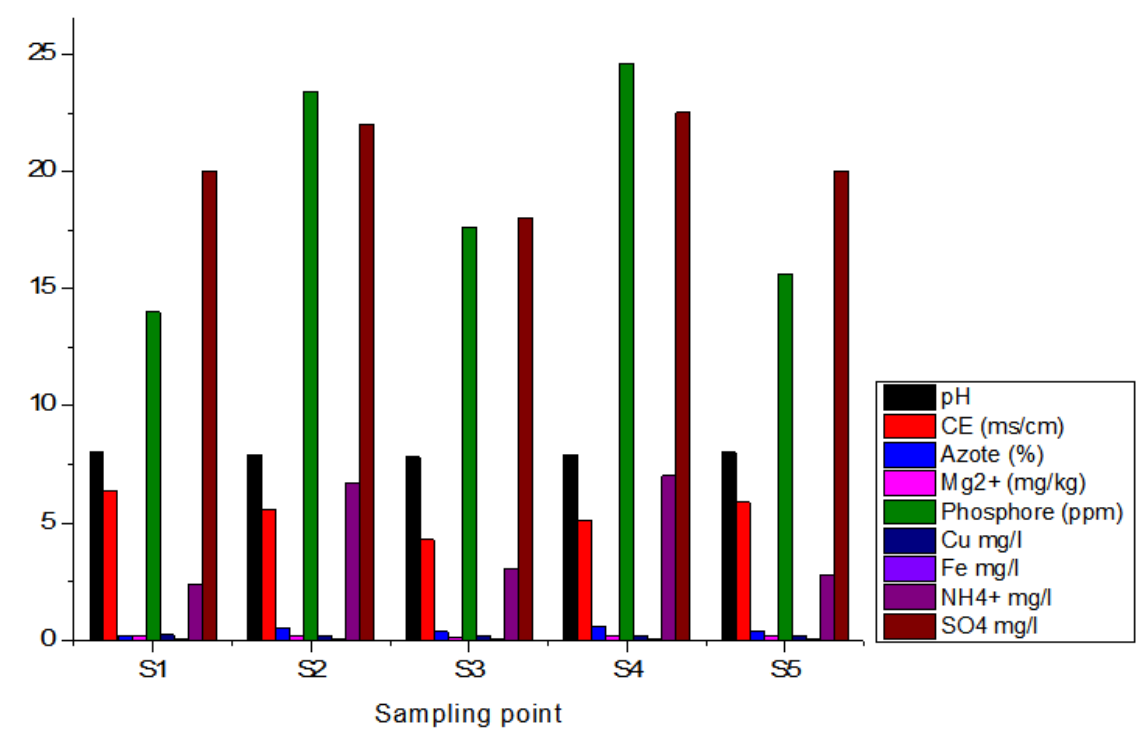

Figure 2 : Physico-chemical analysis of the water at the points

Phosphorus, one of the important nutrients, can be found in various oxidised forms. It is a biogenic element that is essential for the growth of algae. High levels of this element in surface waters can lead to eutrophication. It is an indicator of pollution. However, they have a beneficial effect by playing a regulatory role: they favour all fertilisation phenomena, fruiting and the maturity of vegetative organs. Our results (Figure 2) show that the analysis of the samples for orthophosphates qualifies these waters as excellent quality according to Moroccan water standards, the values encountered are largely lower than those set by the latter.

The variation of the ammonium ion in the water of the sampled points during the three campaigns, the values of ammonium is more accentuated in the second campaign than in the first campaign. For the first campaign, the concentration of the ammonium ion varies from $3 \mathrm{mg} / \mathrm{l}$ to $6 \mathrm{mg} / \mathrm{l}$, which corresponds to the low concentrations that we recorded during the three campaigns. It should be noted that these values are higher than the WHO standard of $0.05 \mathrm{mg} / \mathrm{l}$ for water intended for human consumption. This observed difference could be explained by the application of nitrogen-based fertilisers (NPK fertilisers and urea) which are drained by runoff into the watercourses.
Low concentrations of heavy metals constitute the geochemical background of a certain environment. To assess the impact of a heavy metal in the environment, the mere presence is not sufficient. This impact is potential if the given metal is found at levels of abnormally high concentrations compared to the geochemical background.

Once heavy metals have been released into the environment, either by natural (e.g. weathering) or anthropogenic (e.g. mining) processes from their source, they can be transported by wind via aerosols or by water via water, suspended solids or river bottom sediments; their concentrations are an important parameter to characterise the impact, however it is very important to know the availability of their concentrations in the environment to terrestrial and aquatic organisms. This "availability" of an element to organisms is very much controlled by dissolution and solution from the carrier minerals, and subsequently by adsorption and precipitation of that element by geochemical reactions taking place in water, sediment or aerosols. The degree to which a metal is absorbed or precipitated depends on its intrinsic properties, the physicochemical parameters of the environment $(\mathrm{pH}$ and redox potential) and the nature of the sorbent. 
The sulphate concentrations recorded in the water are very low. They vary between 14 and $25 \mathrm{mg} / \mathrm{l}$. The high values were measured at sites (1 and 4$)$ on the catchment area, with the sampling points coming out of the pits located $400 \mathrm{~m}$ away, but taken from a cocoa plantation at the catchment area.

The magnesium content varies from 0 to $0.2 \mathrm{mg} / \mathrm{l}$, with an average of $0.1 \mathrm{mg} / \mathrm{l}$. Sodium levels ranged from 18 to $22 \mathrm{mg} / \mathrm{l}$. Potassium concentrations are the lowest. They vary from 0.7 to $0.9 \mathrm{mg} / \mathrm{l}$, with an average of $8.5 \mathrm{mg} / \mathrm{l}$ (Figure 2).

\subsection{Modelling}

The stability analysis ensures that the impacts of monthly variation on the suggested model are being minimized. This analysis is conducted by comparing the linear correlations between the measured and simulated EU parameters. The coefficient of definition (R2) and root mean square error (RMSE) evaluate the efficiency of our simulation model, and to compute the amount of error that could be created between observed data.

The consistency test for simulated and measured parameters indicated a high correlation $(\mathrm{R} 2>0.8)$ for nitrogen and phosphate forms (Figure 2). However, the results for dissolved oxygen (DO) and BOD were not as stable (R2 > 0.8). This unsteadiness could be attributed to the pollution source loading from neighboring areas.

This recharge was not well approximated due to the fact that there is no sewerage system at these sites. As shown in Table 5, the electrical conductivity can be computed from the calculated simulated parameters $\mathrm{NH} 4+, \mathrm{NO} 3-$, and $\mathrm{DO}$, while the $\mathrm{pH}$ can be calculated using a three parameter combination (BOD, NO3, and water hardness) with high accuracy $(\mathrm{R} 2=0.75)$. Using the results of the correlation, we created an equation for estimating these parameters by using the simulated parameters.
On the basis of the WQI-NSF calculated using the parameters simulated, many water quality methods have been evaluated, where the quality average rate has been set at $50 \%$ in the WQINSF index. This evaluation process is valuable for testing the reliability, sustainability, and effectiveness of approaches to improve water quality impairment. of water Quality and is also less costly The comparison between NSF WQIs that were derived from simulated and measured parameters over the entire data period was gathered revealed a high degree of correlation $(\mathrm{R} 2=0.82)($ Figure 5$)$. This correlation showed the reliability of the The simulated data for the NSF WQI computation were high.

As previously mentioned, wastewater is dumped into the El Abid River, which has major risks in terms of quality deterioration. Therefore, the wastewater purification plant proposals, among others, were tested to assess their feasibility. Four scenarios were tested on the basis of wastewater treatment efficiency $(30 \%, 45 \%, 80 \%$ and $90 \%$, which represents the complete treatment of the liquid discharge). The appropriate solutions were evaluated in terms of success in improving water quality and reducing costs. As shown in Figure 5, it is not feasible to provide complete treatment of wastewater with $100 \%$ efficiency for the last two plants, P2, P3, which could be explained by other (natural) factors involved in the poor water quality (such as geological structures that are formed by evaporite rocks increasing the anion contained in the water) (Medina et al; 2021). In terms of effectiveness, the scenarios tested showed that treatment of liquid waste at the $25 \%$ level was insufficient to improve water quality conditions in all sections of the stream. However, when the level of treatment exceeded 50\%; it significantly decreased the effects of the liquid discharges.
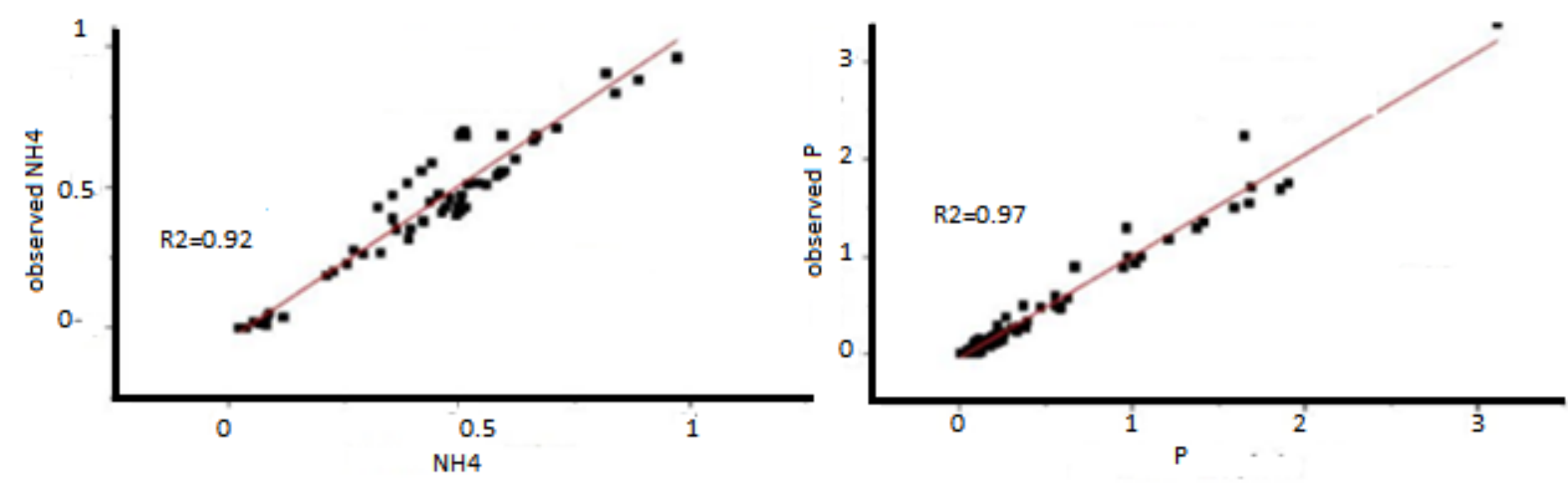

Figure 3 : Simulated and measured NH4, P correlation
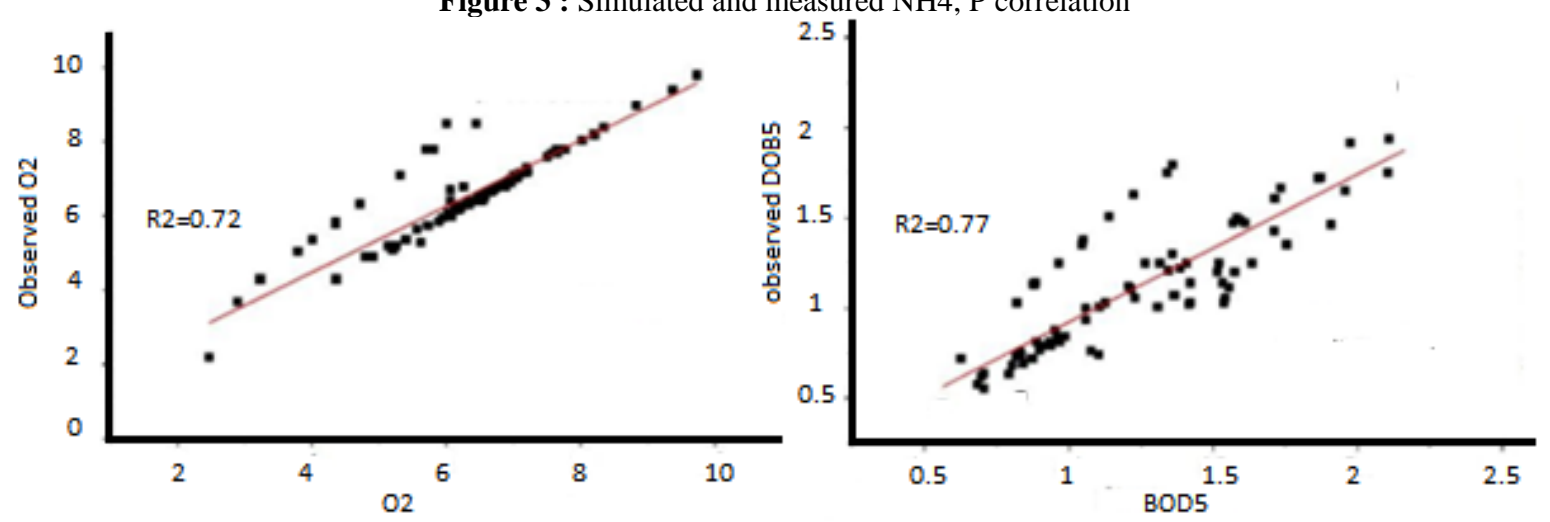

Figure 4: Simulated and measured $\mathrm{O}_{2}$, BDO correlation 
Table 1: Correlation between simulated parameters

\begin{tabular}{|c|l|c|c|}
\hline Parameters & \multicolumn{1}{|c|}{ Correlated parameters } & R2 & RMS \\
\hline Electrical & $\mathrm{NH}_{4}^{+}, \mathrm{NO}^{3-}$ and $\mathrm{OD}$ & 0.62 & 29.3 \\
conductivity & $\mathrm{NO}^{2-}$ and $\mathrm{PO}_{4}^{3-}$ & 0.64 & 7.02 \\
Water hardness (TH) & $\mathrm{BOD}, \mathrm{NO}^{3-}$ and $\mathrm{TH}\left(\right.$ estimated by $\mathrm{NO}^{2-}$ and $\mathrm{PO}_{4}^{3-}$ & 0.75 & 0.16 \\
$\mathbf{p H}$ & & & \\
\hline
\end{tabular}
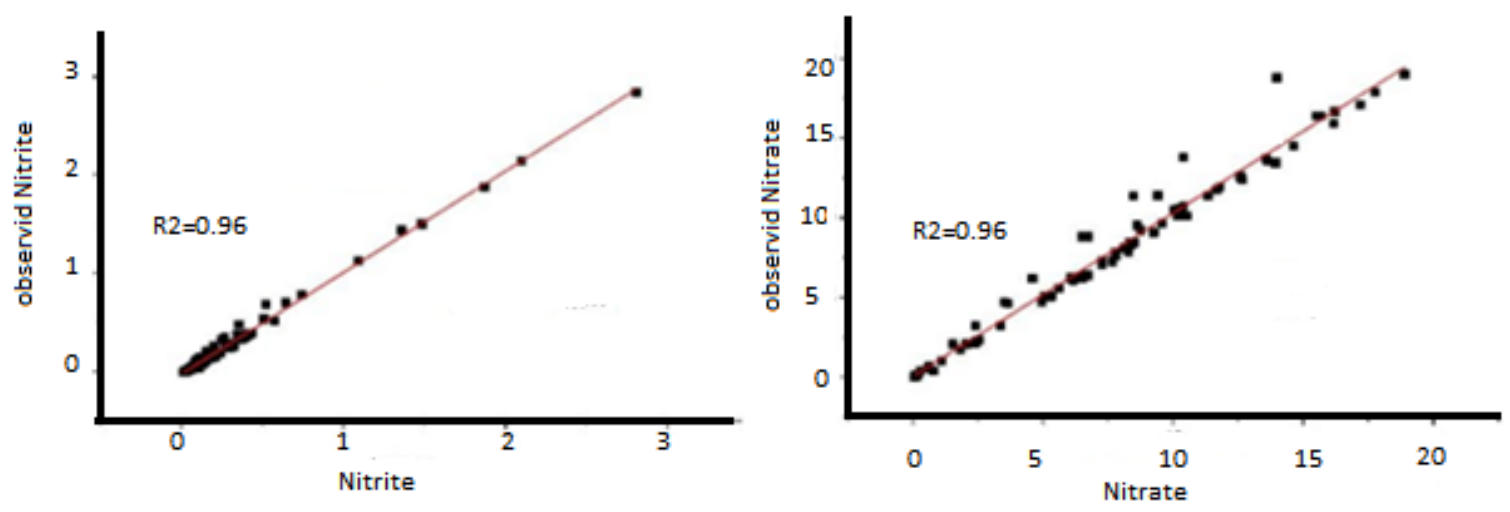

Figure 5: Corrélation entre Ni2- ,Ni3- simulés et mesurés

\section{CONCLUSION}

The purpose of this study was to demonstrate the physicochemical properties and modelling of northern surface waters in Morocco. The results show that the waters are non-aggressive. The waters are medium mineralized with a conductivity between 3 and $5 \mathrm{mS} / \mathrm{cm}$, with an average of $4 \mathrm{mS} / \mathrm{cm}$. The waters in the vicinity of the industrial sites are the most mineralised. The waters most influenced by nitrates are those located in the vicinity of industrial sites. The predominance of chloride-calcium and magnesium facies in the waters of the department is due to the low lithological heterogeneity of the department. The analysis shows that the mineralization of water is influenced by anthropic activities (the grouping is constituted by: $\mathrm{EC}$, cations $(\mathrm{Na}+, \mathrm{Ca} 2+$ and $\mathrm{K}+$ ), anions (Cl-, $\mathrm{HCO} 3-$, SO42-) and NO3-in its negative part. The presence of nitrate (NO3-) in this grouping has a superficial origin and testifies to anthropic pollution. This explains a mineralization linked to the industrial activities of the department produced on the surface of the soil, then carried away with the runoff water. These results highlight the strong anthropogenic pressure on surface water quality. The modelling system can reduce the analytical cost of individual samples and assist in the selection and planning of these solutions by decision makers. Simulation through this chemical and biological process by solving mass balance equations is an effective tool that can help predict water quality and select appropriate and relevant solutions to the challenge of improving water quality. In the meantime, it is clear that these waters are not suitable for human consumption.
Their consumption without prior treatment exposes the population to health risks.

\section{REFERENCES}

Aboubakar, A., El Hajjaji, S., Douaik, A., Mfopou Mewouo, Y. C., Birang a Madong, R. C., Dahchour, A., ... \& Labjar, N. (2021). Heavy metal concentrations in soils and two vegetable crops (Corchorus olitorius and Solanum nigrum L.), their transfer from soil to vegetables and potential human health risks assessment at selected urban market gardens of Yaoundé, Cameroon. International Journal of Environmental Analytical Chemistry, 1-22.

Al Rawashdeh, R., Campbell, G., \& Titi, A. (2016). The socioeconomic impacts of mining on local communities: The case of Jordan. The Extractive Industries and Society, 3(2), 494-507.

Ayenagbo, K., Kimatu, J. N., Gondwe, J., \& Rongcheng, W. (2011). The transportation and marketing implications of sand and gravel and its environmental impact in Lome-Togo. Journal of economics and International Finance, 3(3), 125-138.

Chowdhury, R. M., Ankon, A. A., \& Bhuiyan, M. K. Water Quality Index (WQI) of Shitalakshya River near Haripur Power Station, Narayanganj, Bangladesh. In Proceedings of the 5th International Conference on Civil Engineering for Sustainable Development (ICCESD 2020). 
Fattah, G., Ghrissi, F., Mabrouki, J., \& Kabriti, M. (2021). Control of physicochemical parameters of spring waters near quarries exploiting limestone rock. In E3S Web of Conferences Vol. 234, p. 00018).

Fattah, G., Mabrouki, J., Ghrissi, F., Azrour, M.(2021).Proposal for a high-resolution particulate matter (PM10 and PM2.5) capture system, comparable with hybrid system-based internet of things: case of quarries in the western Rif, Morocco. Pollution.

Garcia-del-Real, J., Barakos, G., \& Mischo, H. (2020). Space mining is the industry of the future... or maybe the present. In SME annual meeting February. 23-26.

Gong, F., \& Jiang, X. (2021). Wireless sensor-based soil composition detection and high-efficiency water-saving irrigation in agricultural water conservancy applications. Arabian Journal of Geosciences, 14(16), 1-12.

Habert, G., Miller, S. A., John, V. M., Provis, J. L., Favier, A., Horvath, A., \& Scrivener, K. L. (2020). Environmental impacts and decarbonization strategies in the cement and concrete industries. Nature Reviews Earth \& Environment, 1(11), 559573.

Hellegers, P., Immerzeel, W., \& Droogers, P. (2013). Economic concepts to address future water supply-demand imbalances in Iran, Morocco and Saudi Arabia. Journal of hydrology, 502, 62-67.

Mabrouki, J., Benbouzid, M., Dhiba, D., \& El Hajjaji, S. (2020). Simulation of wastewater treatment processes with Bioreactor Membrane Reactor (MBR) treatment versus conventional the adsorbent layer-based filtration system (LAFS). International Journal of Environmental Analytical Chemistry, 1-11.

Mabrouki, J., El Yadini, A., Bencheikh, I., Azoulay, K., Moufti, A., \& El Hajjaji, S. (2018, July). Hydrogeological and hydrochemical study of underground waters of the tablecloth in the vicinity of the controlled city dump mohammedia (Morocco). In International Conference on Advanced Intelligent Systems for Sustainable Development. 22-33.

Mabrouki, J., Fattah, G., Al-Jadabi, N., Abrouki, Y., Dhiba, D., Azrour, M., \& El Hajjaji, S. (2021). Study, simulation and modulation of solar thermal domestic hot water production systems. Modeling Earth Systems and Environment, 1-10.

Mabrouki, J., Moufti, A., Bencheikh, I., Azoulay, K., El Hamdouni, Y., \& El Hajjaji, S. (2019, July). Optimization of the Coagulant Flocculation Process for Treatment of Leachate of the Controlled Discharge of the City Mohammedia (Morocco). In International Conference on Advanced Intelligent Systems for Sustainable Development. 200-212.

Medina, F. G. C., Ventura-Houle, R., Rodríguez, L. H., Lara, G. N. R., Mansilla, O. G., \& Ramírez, E. N. (2021). Water-rock interactions in a karst aquifer located in southwestern Tamaulipas, Mexico. Carbonates and Evaporites, 36(3), 1-11.

Mor, R. S., Bhardwaj, A., Singh, S., \& Sachdeva, A. (2019). Productivity gains through standardization-of-work in a manufacturing company. Journal of Manufacturing Technology Management.
Pan, R., Liu, G., Zeng, Y., He, X., Ma, Z., Wei, Y., ... \& Tao, L. (2021). A multi-responsive self-healing hydrogel for controlled release of curcumin. Polymer Chemistry, 12(16), 2457-2463.

Paule-Mercado, M. C. A., Salim, I., Lee, B. Y., Memon, S., Sajjad, R. U., Sukhbaatar, C., \& Lee, C. H. (2018). Monitoring and quantification of stormwater runoff from mixed land use and land cover catchment in response to land development. Ecological indicators, 93, 1112-1125.

Prasad, B., Rao, P. R., \& Tigga, A. (2021). Groundwater quality assessment using the weighted arithmetic index method in the selected villages of Butchayyapeta Mandal, Visakhapatnam, Andhra Pradesh, India. Environmental Monitoring and Assessment, 193(11), 1-17.

Said, S. S., Campbell, S., \& Hoare, T. (2019). Externally addressable smart drug delivery vehicles: Current technologies and future directions. Chemistry of Materials, 31(14), 49714989.

Suaria, G., Achtypi, A., Perold, V., Lee, J. R., Pierucci, A., Bornman, T. G., ... \& Ryan, P. G. (2020). Microfibers in oceanic surface waters: A global characterization. Science advances, 6(23), eaay8493.

Zotou, I., Tsihrintzis, V. A., \& Gikas, G. D. (2020). Water quality evaluation of a lacustrine water body in the Mediterranean based on different water quality index (WQI) methodologies. Journal of Environmental Science and Health, Part A, 55(5), 537-548. 